\title{
Dielectric properties of BNT-xBT prepared by hydrothermal process
}

\author{
Natheer B. Mahmood and Emad K. Al-Shakarchi* \\ Physics Department, College of Science \\ Al-Nahrain University, Baghdad, Iraq \\ *eks2000@ hotmail.com
}

Received 1 April 2017; Revised 18 May 2017; Accepted 19 May 2017; Published 22 June 2017

\begin{abstract}
The BNT ceramic sample might be a good replacement for PZT piezoelectric in industrial applications, especially in energy harvesting from crystal vibrations. In order to enhance the performance of BNT ceramic, the solid solution was chosen by substitution with $\mathrm{Ba}^{+2}$ at Morphtropic Phase Boundary (MPB). The BNT- $x \mathrm{BT}$ powders with $x=1,0.07,0.06$ and 0 were prepared by the hydrothermal method with average particle size $(65-150 \mathrm{~nm})$ at $\left(90^{\circ} \mathrm{C} / 72 \mathrm{~h}\right)$. The ceramic disc was sintered at $\left(1150^{\circ} \mathrm{C} / 4 \mathrm{~h}\right)$ and showed excellent relative density of about 96\%. The results of X-ray diffraction (XRD) confirmed the MPB for $x=0.06$ and 0.07, while the BNT had a rhombohedral structure and BT had a tetragonal structure. The dielectric measurements showed that BNT, BNT-7BT, BNT-6BT behave as the relaxator ferroelectric and showed a strong dependence on frequency, especially in the MPB region while BT behaves as a normal ferroelectric. Both the Curie temperature and depolarization temperature decrease at the MPB region and showed strong dependency on frequency.
\end{abstract}

Keywords: Ferroelectric behavior; piezoelectric behavior; energy harvesting; hydrothermal process.

\section{Introduction}

The bismuth sodium titanate, BNT-system, has chemical formula $\mathrm{Bi}_{0.5} \mathrm{Na}_{0.5} \mathrm{TiO}_{3}$ with a complex A-site perovskite application. The BNT has a Rhombohedral perovskite structure with $\mathrm{Na}^{+1}$ and $\mathrm{Bi}^{+3}$ distributed sequentially in A-site. ${ }^{1}$ Many studies focused on BNT as a ceramic, and focused on this compound as a lead-free piezoelectric or the replacement for PZT in industrial applications especially in energy harvesting from crystal vibrations. The BNT has several drawbacks in the alternative replacement for PZT such as the high value of the coercive electric field $(>60 \mathrm{kV} /$ $\mathrm{cm})$. This difficulty is making the limitation in the applications of BNT. ${ }^{2-4}$ The BNT is considered as the relaxator ferroelectric that has a high Curie temperature $\left(320^{\circ} \mathrm{C}\right)$, and high depolarization temperature of about $\left(>200^{\circ} \mathrm{C}\right)$ that is a second drawback of BNT. One of the possible solutions to overcome the drawbacks in BNT, is using a solid solution by substituting of either A or B sites or by creating an oxygen vacancy. The last will lead to a fast degradation of polarization. The substitution of A and B sites is suitable to solve the problem of high coercive electric field. ${ }^{4-6}$ To overcome the second drawback, one must be decreasing the value of depolarization temperature from $200^{\circ} \mathrm{C}$ to nearly room temperature in order to enhance the piezoelectric performance. In this research, the substitution of A-site in BNT with $\mathrm{Ba}^{+2}$ had been done, it had an ionic radius greater than $(\mathrm{Bi}, \mathrm{Na})$. The substitution of $\mathrm{Ba}^{+2}$ led to the creation of a solid solution between bismuth sodium titanate and barium titanate (BT) $\left(\left(\mathrm{Bi}_{0.5} \mathrm{Na}_{0.5}\right)_{1-x} \mathrm{Ba}_{x} \mathrm{TiO}_{3}\right)$. It had a direct effect on the decreasing the depolarization temperature because the $\mathrm{BT}$ was ferroelectric with a Curie temperature of about $120^{\circ} \mathrm{C}$.

\section{Experimental Work}

A hydrothermal method was used in the preparation of BNT$x \mathrm{BT}$ powder with $x=0,0.06,0.07$ and 1 . The preparation of the powder started by adding $\mathrm{TiCl}_{4}$ gradually to propanol with a ratio of 1:10 under constant stirring to get a yellow gummy solution. The distilled water of $10 \mathrm{ml}$ was added to this solution to get a transparent solution (Sol-1). The bismuth nitrate was added to $10 \mathrm{ml}$ of concentrated hydrochloric acid, then the sodium acetate and/or barium nitrate were added with stoichiometric amounts to the resultant solution producing a transparent solution (Sol-2). The mixing of (Sol-1) and (Sol-2) with oxalic acid at stoichiometric ratio was done under warm conditions, and with stirring at $90^{\circ} \mathrm{C} / 15 \mathrm{~min}$. Then a gradual dropping of $10 \mathrm{M}$ solution of sodium hydroxide was added to the oxalate solution with continuous stirring at $90^{\circ} \mathrm{C} /$ $72 \mathrm{~h}^{7-10}$ The resultant powder was washed and filtered for five times with distilled water, then characterized by X-ray diffraction XRD analysis. The steps for preparation of BNT via a hydrothermal process is shown in Fig. 1.

The resultant powder was pressed into a disc by $250 \mathrm{MPa}$ then sintered at $\left(1150^{\circ} \mathrm{C} / 4 \mathrm{~h}\right)$ for all samples. The prepared samples were analyzed by XRD that was carried out at room temperature using Panalytical diffractometer with $\mathrm{Cu} \mathrm{k}_{\alpha 1}$ wavelength $(\lambda=1.54064 \AA)$. The XRD computational analyses were performed using different software packages to

This is an Open Access article published by World Scientific Publishing Company. It is distributed under the terms of the Creative Commons Attribution 4.0 (CC-BY) License. Further distribution of this work is permitted, provided the original work is properly cited. 


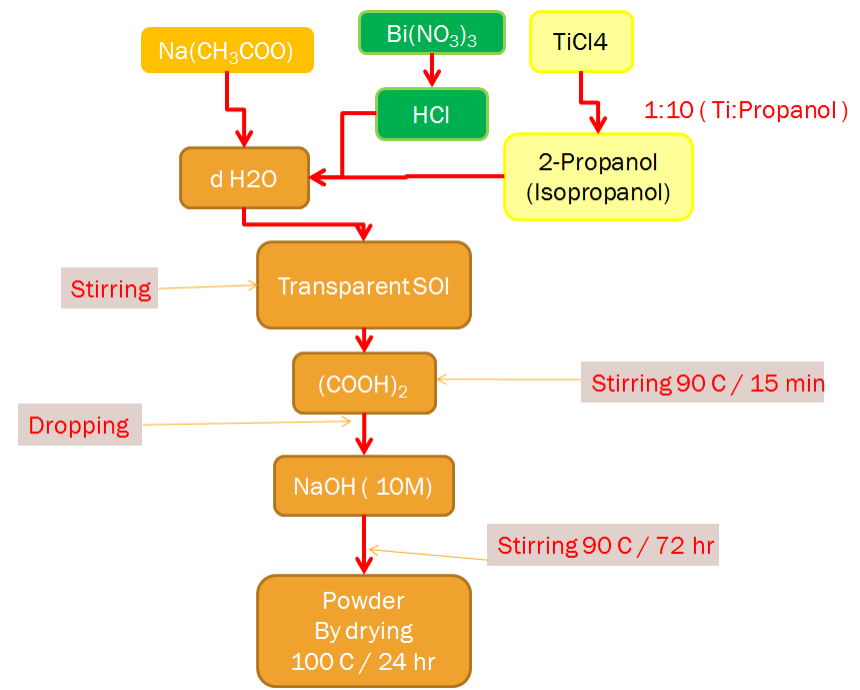

Fig. 1. Steps for preparation BNT- $x$ BT via hydrothermal method.

determine the lattice constants, symmetry, and resolving the overlapping of MPB tetragonal and rhombohedral phases. The crystal impact match V $3^{11}$ and crystal impact diamond V4 software ${ }^{12}$ were used for the phase identification by unit cell refinement and space group determination. A diffraction database was used for the specification of the produced powder PDF\# 89-1428 for $\mathrm{BaTiO}_{3},{ }^{13}$ PDF\# 05-0626 for $\mathrm{BaTiO}_{3},{ }^{14}$ International Center for Diffraction Data (ICDD), ${ }^{15}$ COD\#1507756 for $\mathrm{BaTiO}_{3},{ }^{18} \mathrm{COD} \# 2100858$ for $\mathrm{BaTiO}_{3},{ }^{16} \mathrm{COD \#} 2103295$ for $\mathrm{Bi}_{0.5} \mathrm{Na}_{0.5} \mathrm{TiO}_{3},{ }^{2}$ COD\#2102068 for $\mathrm{Bi}_{0.5} \mathrm{Na}_{0.5} \mathrm{TiO}_{3},{ }^{17}$ and COD\#1532924 for $\mathrm{Bi}_{0.5} \mathrm{~K}_{0.5} \mathrm{TiO}_{3}{ }^{18}$ from Crystallography Open Database were used for the specifications of the produced powder.

The dielectric measurement was performed using TEGAM-3550 LCR meter at $1 \mathrm{~V}$. The disc was placed in a suitable testing quartz cell under vacuum. ${ }^{19}$ The ceramic disc was polished and sandwiched between two gold electrodes coated on the surface by sputtering. The dielectric measurement had been performed by changing the temperature from room temperature to $500^{\circ} \mathrm{C}$ at different frequencies $1 \mathrm{kHz}$, $10 \mathrm{kHz}, 100 \mathrm{kHz}, 1 \mathrm{MHz}, 3 \mathrm{MHz}$ and $5 \mathrm{MHz}$. The ferroelectric relaxation behavior with phase diffusion transition was deduced according to the modified Curie-Wise relation equation $^{9}$

$$
\frac{1}{\varepsilon^{\prime}}-\frac{1}{\varepsilon_{\max }^{\prime}}=C^{-\gamma}\left(T-T_{\max }\right)^{\gamma},
$$

where $\varepsilon^{\prime}$ is the dielectric constant, $\varepsilon_{\text {max }}^{\prime}$ is the maximum value of the dielectric constant, $C$ is the Curie constant, $T_{\max }$ is the temperature at $\varepsilon_{r \text { max }}$ and $\gamma$ is the diffusion coefficient of the phase transition.

\section{Results and Discussion}

The substitution with barium $\left(\mathrm{Ba}^{+2}\right)$, had an equivalent valence number of $\mathrm{Ba}^{+2}$ and $\left(\mathrm{Bi}_{0.5}^{+3} \mathrm{Na}_{0.5}^{+1}\right)^{+2}$. The net valence of
$(\mathrm{Bi}, \mathrm{Na})$ is $(+2)$, so $\mathrm{Ba}^{+2}$ is suitable for the replacement of both $\mathrm{Bi}$ and $\mathrm{Na}$ together by the following equation. The $\mathrm{BaTiO}_{3}$ (BT) has a tetragonal phase while BNT has a rhombohedral, so MPB could be easily obtained. The compound BT has a high value of dielectric constant which makes the substitution of $\mathrm{Ba}^{+2}$ suitable for energy harvesting applications. $^{20-22}$

$$
\begin{aligned}
& {[y]\left(\mathrm{Bi}_{0.5} \mathrm{Na}_{0.5} \mathrm{TiO}_{3}\right)+[1-y]\left(\mathrm{BaTiO}_{3}\right)} \\
& \quad \rightarrow\left(\mathrm{Bi}_{0.5} \mathrm{Na}_{0.5}\right)_{y} \mathrm{Ba}_{1-y} \mathrm{TiO}_{3},
\end{aligned}
$$

where $y=1,0.07,0.06$ and 0 for BNT, BNT-7BT, BNT-6BT and BT, respectively. The XRD analysis showed that BNT had a rhombohedral phase, while BT had a tetragonal phase. Both phases BNT-6BT and BNT-7BT had MPB, they had both a tetragonal and rhombohedral phase. The XRD patterns for BNT- $x$ BT samples are shown in Fig. 2, the MPB recognized by the appearance of (111) regarding to the tetragonal phase. It was overlapped with the dual peaks of rhombohedral $(02 \overline{2})(006)$, around $2 \theta=40$. The rhombohedral single peak (024) was overlapped with a tetragonal dual peak (020)(002) that appears around $(2 \theta=46)$, the deconvolution of these overlapping is shown in Fig. 3.

The BNT-6BT had MPB with a rhombohedral lattice $(a=b=5.4955 \AA, c=13.387 \AA, \alpha=\beta=90$ and $\gamma=120$ ) and a tetragonal lattice with $(a=b=3.8871 \AA$, $c=3.8971 \AA$ and $\alpha=\beta=\gamma=90$ ). The BNT-7BT had MPB with the same lattice constants of BNT-6BT tetragonal lattice, but there was a slight difference in the $c$-axis of the rhombohedral lattice $(c=13.5276)$ as shown in Table 1 . The relative density of the sintered disc was $(96 \%, 94 \%, 94 \%$, and $70 \%$ ) for BNT, BNT-7BT, BNT6BT and BT, respectively. The high density of the ceramic discs was due to the successful the sintering process. The output of SEM showed the particle size of the prepared powder in the range (60-150 nm), while the grain size was about 1, 0.8, 0.7, 1 for BNT, BNT-7BT, BNT6BT and BT, respectively. The particle

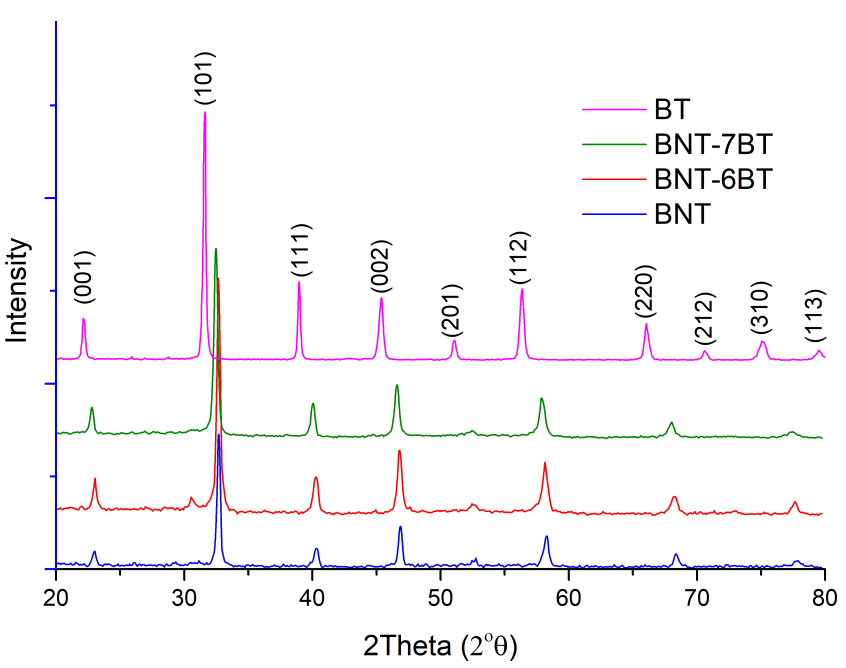

Fig. 2. XRD patterns for BNT, BNT6BT, BNT-7BT and BT. 


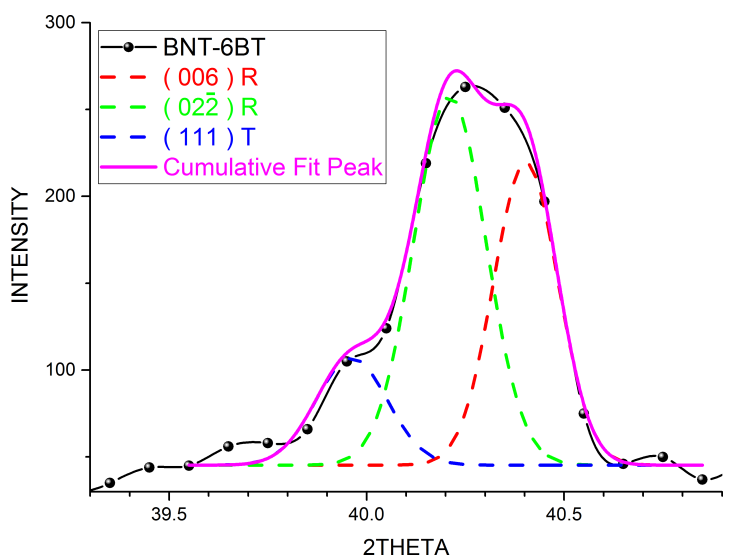

(a)

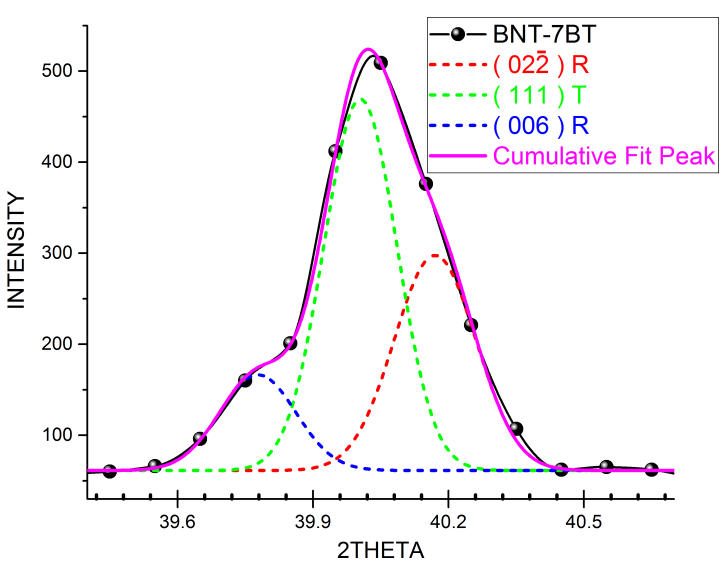

(c)

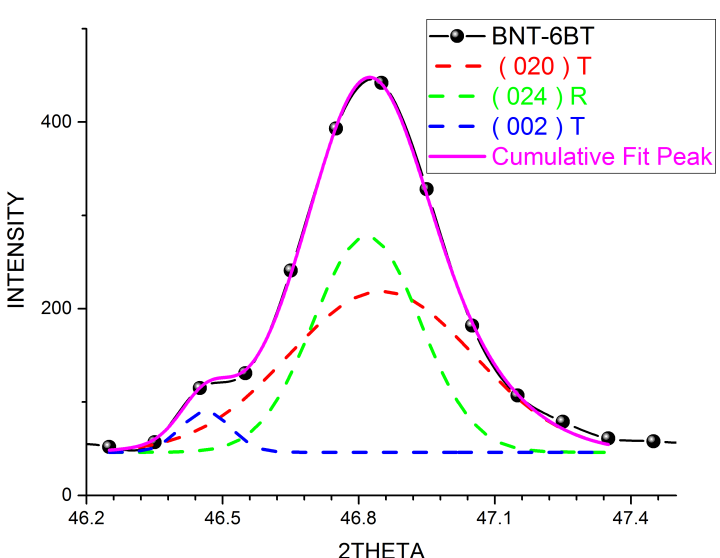

(b)

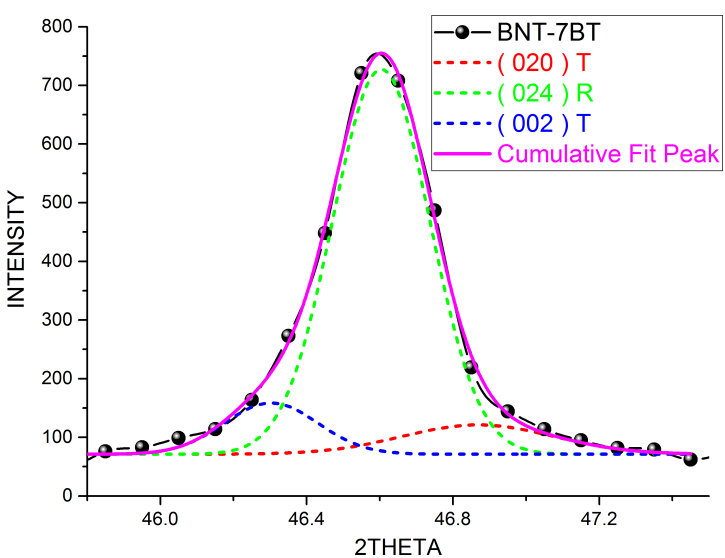

(d)

Fig. 3. De-convolution of the overlapping of tetragonal and rhombohedral peaks.

and grain size for BNT- $x$ BT powder and ceramics were shown in Fig. 4.

The dielectric constant and loss factor as a function of temperature was a good indication to show the relaxator behavior of ferroelectrics. ${ }^{23}$ The samples BNT, BNT-6BT, BNT-7BT showed the relaxator behavior of ferroelectrics. The results of dielectric measurements for BNT ceramic showed the depolarization temperature above $200^{\circ} \mathrm{C}$. The

Table 1. The XRD results for BNT- $x \mathrm{BT}$.

\begin{tabular}{|c|c|c|c|c|c|c|c|}
\hline \multirow{2}{*}{$\frac{\text { Sample }}{\text { BNT }}$} & \multirow{2}{*}{$\frac{x}{1}$} & \multirow{2}{*}{$\begin{array}{l}\text { Chemical composition } \\
\mathrm{Bi}_{0.5} \mathrm{Na}_{0.5} \mathrm{TiO}_{3}\end{array}$} & \multirow{2}{*}{$\begin{array}{l}\text { Space group } \\
\text { R } 3 \text { c (161) } \\
\text { Rhombohedral }\end{array}$} & \multicolumn{2}{|c|}{$\begin{array}{l}\text { Lattice parameter } \\
(\AA) / \text { Angle }\end{array}$} & \multirow[t]{2}{*}{ Space group } & \multirow[t]{2}{*}{ Lattice parameter () } \\
\hline & & & & $\begin{array}{l}A=5.490 \\
B=5.490 \\
C=13.387\end{array}$ & $\begin{array}{c}\alpha=\beta=90 \\
\gamma=120\end{array}$ & & \\
\hline BNT-7BT & 0.07 & $\mathrm{Bi}_{0.465} \mathrm{Na}_{0.465} \mathrm{Ba}_{0.07} \mathrm{TiO}_{3}$ & $\begin{array}{l}\text { R } 3 \text { c (161) } \\
\text { Rhombohedral }\end{array}$ & $\begin{array}{l}A=5.4955 \\
B=5.4955 \\
C=13.5276\end{array}$ & $\begin{array}{c}\alpha=\beta=90 \\
\gamma=120\end{array}$ & P 4 mm (99) Tetragonal & $\begin{array}{l}\mathrm{A}=3.8871 \\
\mathrm{~B}=3.8871 \\
\mathrm{C}=3.8971\end{array}$ \\
\hline BNT-6BT & 0.06 & $\mathrm{Bi}_{0.47} \mathrm{Na}_{0.47} \mathrm{Ba}_{0.06} \mathrm{TiO}_{3}$ & $\begin{array}{l}\text { R } 3 \text { c (161) } \\
\text { Rhombohedral }\end{array}$ & $\begin{array}{l}A=5.4955 \\
B=5.4955 \\
C=13.387\end{array}$ & $\begin{array}{c}\alpha=\beta=90 \\
\gamma=120\end{array}$ & P 4 mm (99) Tetragonal & $\begin{array}{l}\mathrm{A}=3.8871 \\
\mathrm{~B}=3.8871 \\
\mathrm{C}=3.8971\end{array}$ \\
\hline BT & 0 & $\mathrm{BaTiO}_{3}$ & & & & P 4 mm (99) Tetragonal & $\begin{aligned} A & =3.99 \\
B & =399 \\
C & =4.07\end{aligned}$ \\
\hline
\end{tabular}




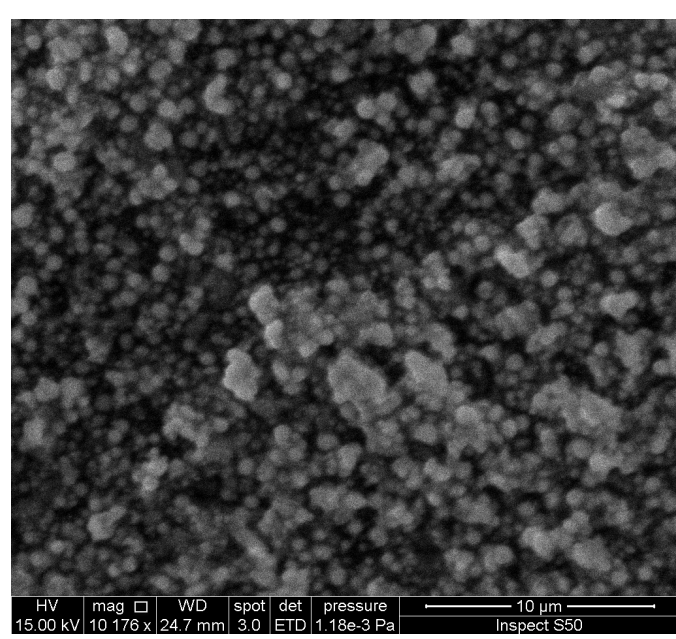

(a)

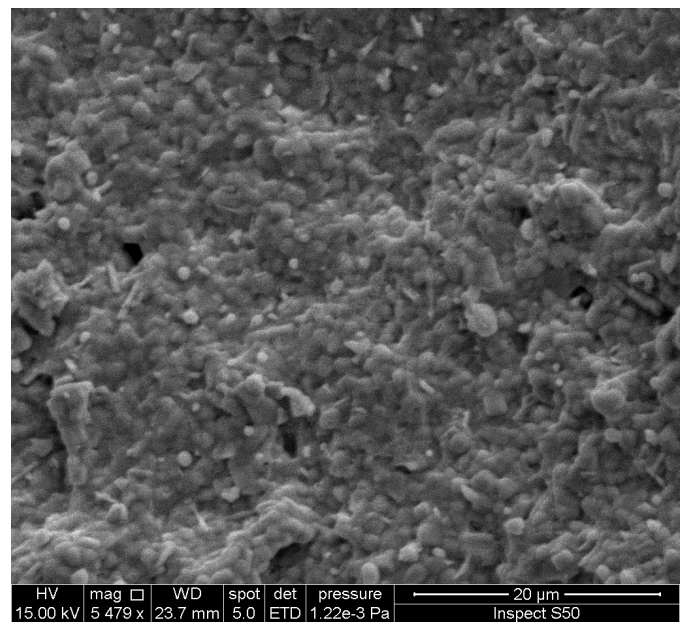

(c)

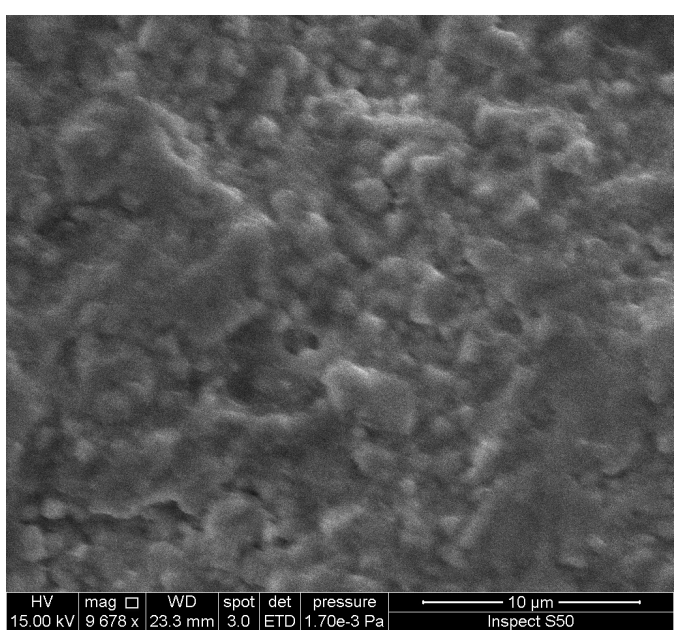

(b)

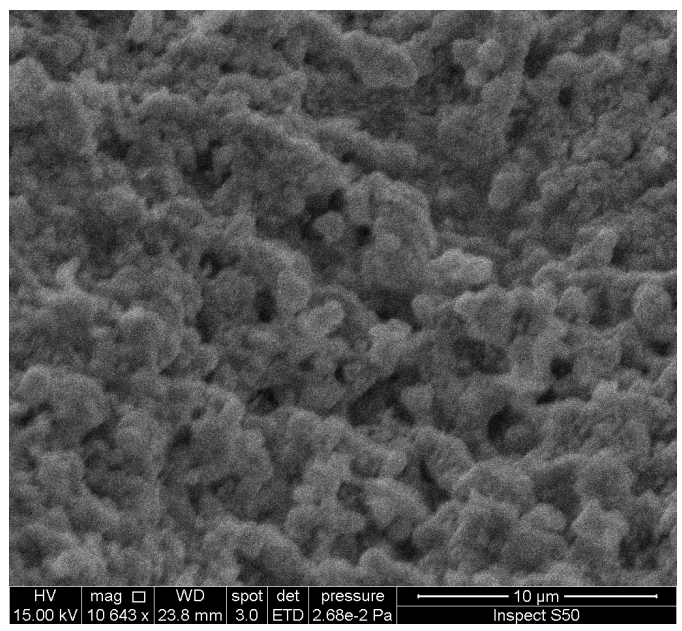

(d)

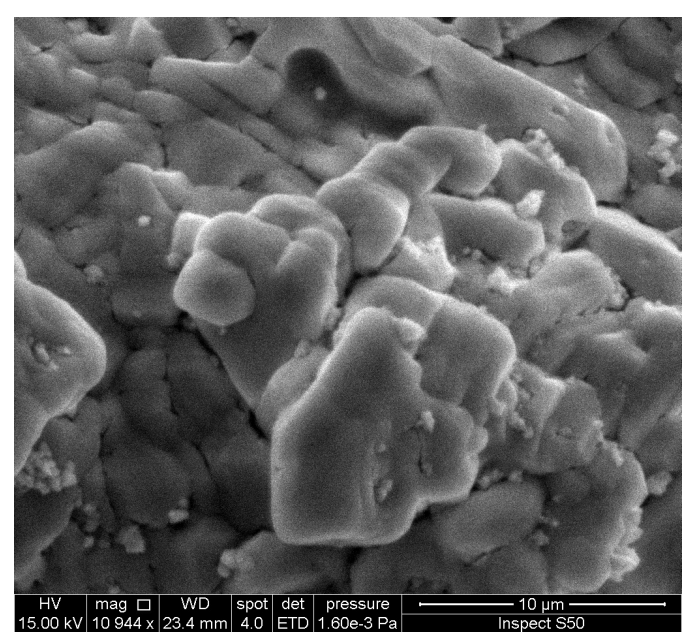

(e)

Fig. 4. SEM image (a) BNT powder, (b) BNT ceramic, (c) BNT-6BT ceramic, (d) BNT-7BT ceramic, (e) BT ceramic. 


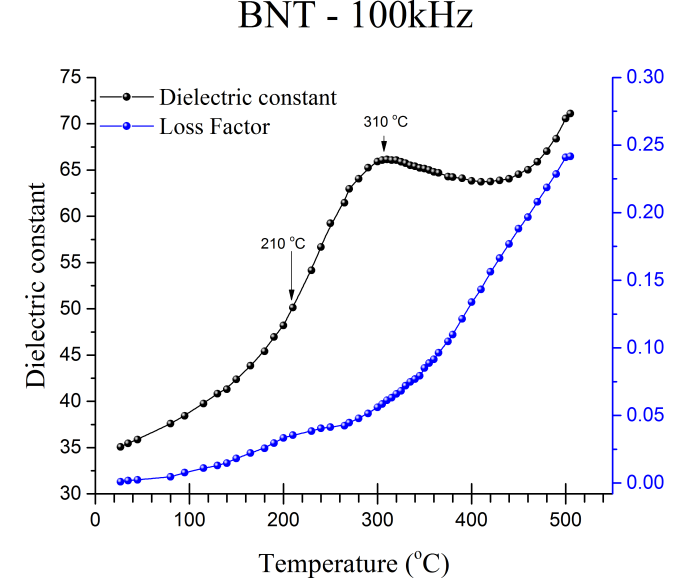

(a)

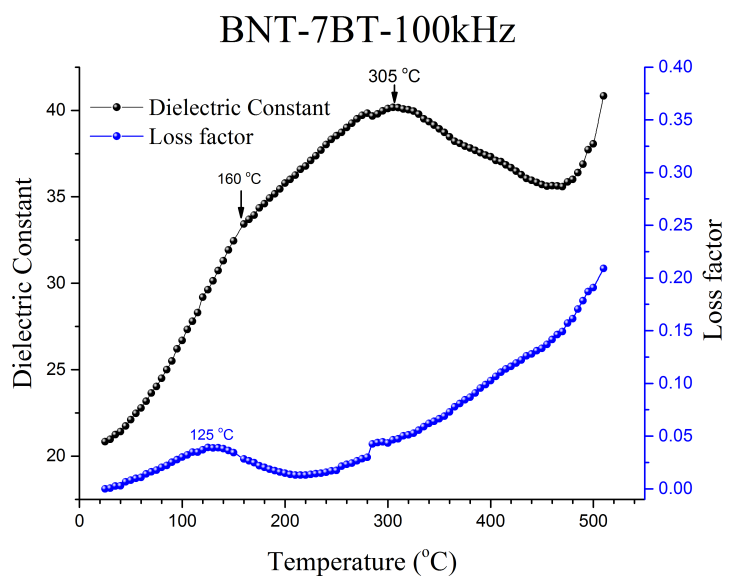

(c)

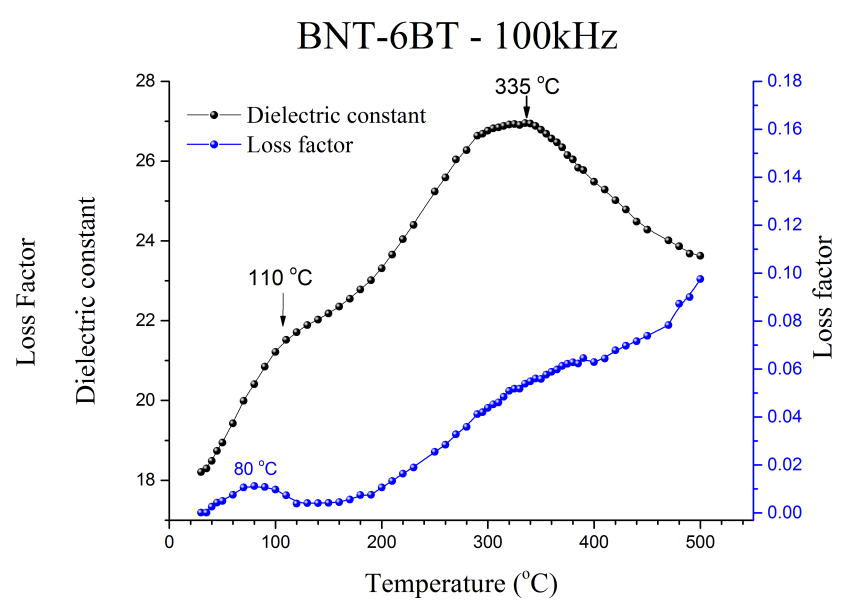

(b)

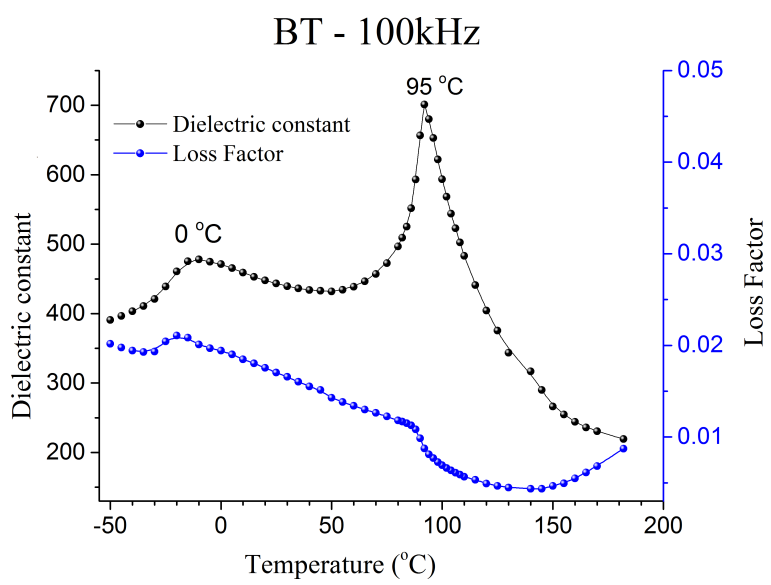

(d)

Fig. 5. Dielectric constant and loss factor as a function of temperature for (a) BNT, (b) BNT-6BT, (c) BNT-7BT, (d) BT.

value of Curie temperature had a maximum temperature for BNT around $300^{\circ} \mathrm{C}$ depending on the frequency as shown in Fig. 5(a). While BNT-6BT had a Curie temperature in the range $\left(300-350^{\circ} \mathrm{C}\right)$, and decreased as frequency increased. The depolarization temperature was about $\left(80^{\circ} \mathrm{C}\right)$ depending on the frequency as shown in Fig. 5(b). The Curie temperature for BNT-7BT was close to $300^{\circ} \mathrm{C}$ and varied with frequency. While the depolarization temperature was about $120^{\circ} \mathrm{C}$ and varied with frequency as shown in Fig. 5(c). The dielectric measurement of the BT-sample exhibited the presence of normal ferroelectrics. The Curie temperature of the BT was about $100^{\circ} \mathrm{C}$. There was another transition temperature that appeared at about $5^{\circ} \mathrm{C}$ that was related to the transition from orthorhombic (Amm2) to the tetragonal (P4mm) as shown in Fig. 5(d).

The diffusion coefficient of transition $(\gamma)$ had the value in the range (1-2), if $\gamma=1$ means the normal ferroelectrics, whereas $\gamma=2$ means the ideal relaxator ferroelectrics. ${ }^{24,25}$ The diffusion coefficient of BNT was in the range (1.2-1.6) and varied with frequency. The frequency increases led to increase in the value of the diffusion coefficient i.e., increasing the frequency led towards ideal relaxator ferroelectrics as shown in Fig. 6(a). The diffusion coefficient for BT was about the one that means the behavior was normal ferroelectrics and frequency independent, as shown in Fig. 6(d). The diffusion coefficient for BNT-6BT and BNT-7BT was in the range (1.41.95). It was greater than BNT and strongly depends on frequency, as shown in Figs. 6(b)-6(c). The MPB region for BNT-6BT and BNT-7BT showed a strong dependence on the diffusion coefficient of transition. Increasing the frequency was tending to increase $\gamma$ while BNT showed a little dependence on frequency. The BT sample had a fixed value of diffusion coefficient and was frequency-independent, and the behavior was similar to normal ferroelectrics, as shown in Fig. 7(a). The Curie temperature for BNT- $x$ BT was frequency dependent, especially in the BNT-7BT sample, while in the BT sample the Curie temperature was frequency independent as shown in Fig. 7(b). The depolarization temperature for the dielectric constant curve was $T_{d 1}$, and the second depolarization temperature in the loss factor curve was $\left(T_{d 2}\right)$.

There was no significant value of $T_{d 1}$ and $T_{d 2}$ for BT sample, while for BNT the $T_{d 1}$ decreased with frequency 


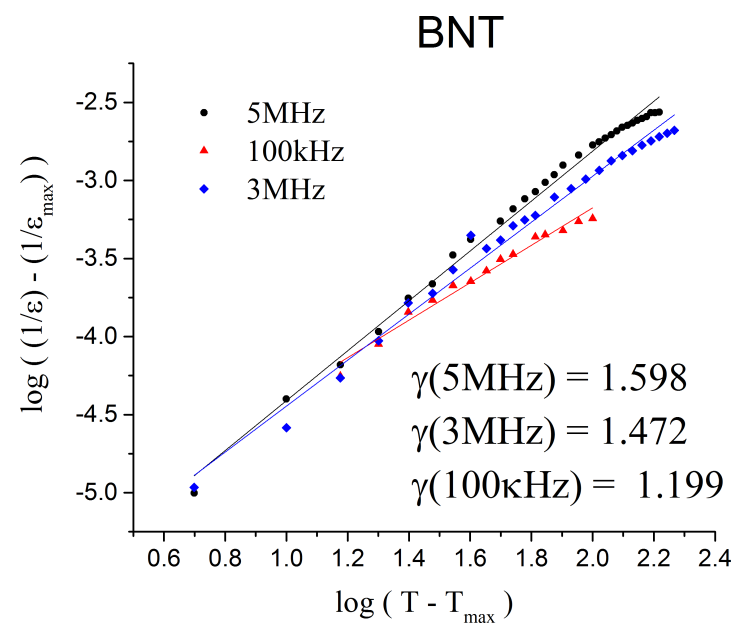

(a)

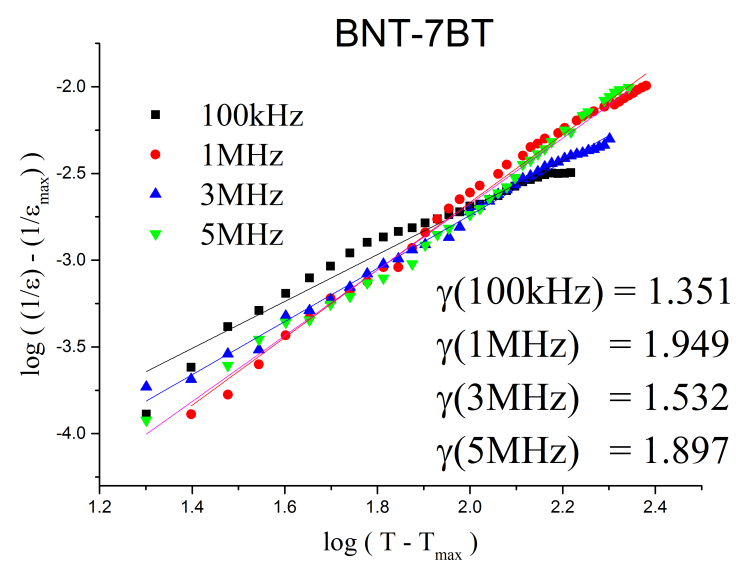

(c)

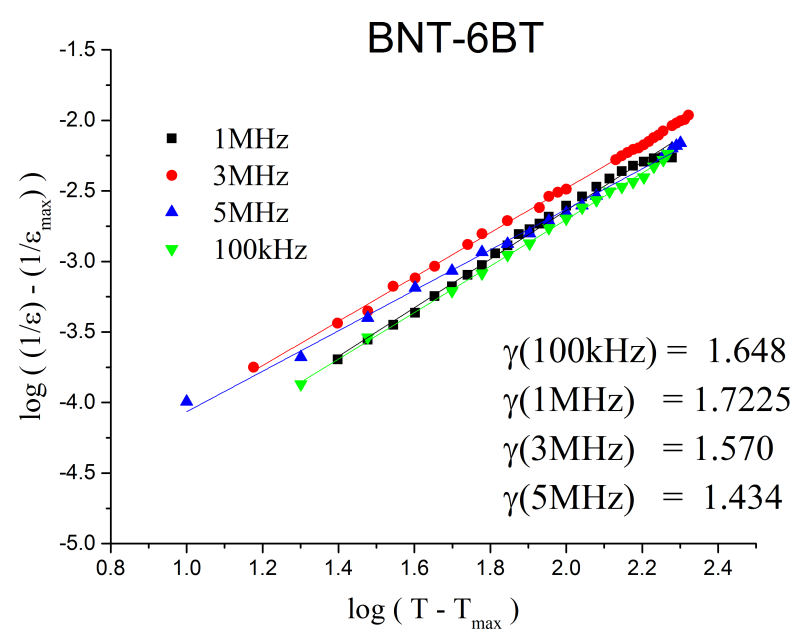

(b)

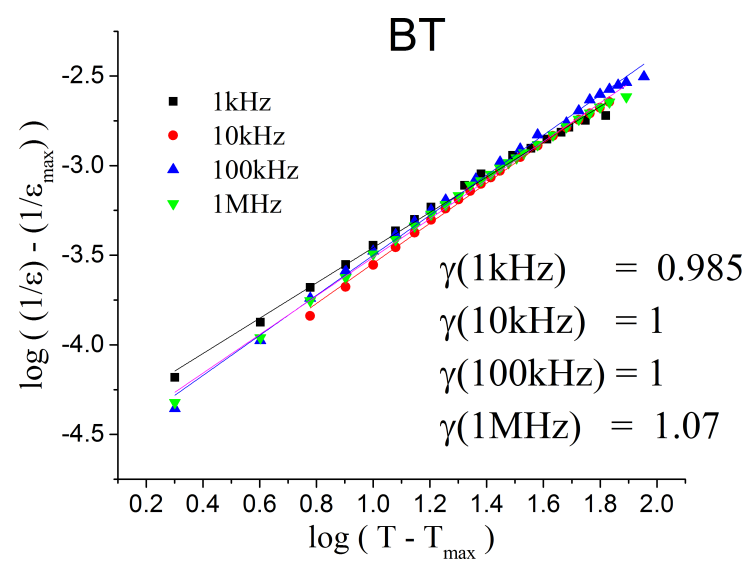

(d)

Fig. 6. The diffusion coefficient of transition $(\gamma)$ for (a) BNT, (b) BNT-6BT, (c) BNT-7BT, (d) BT.

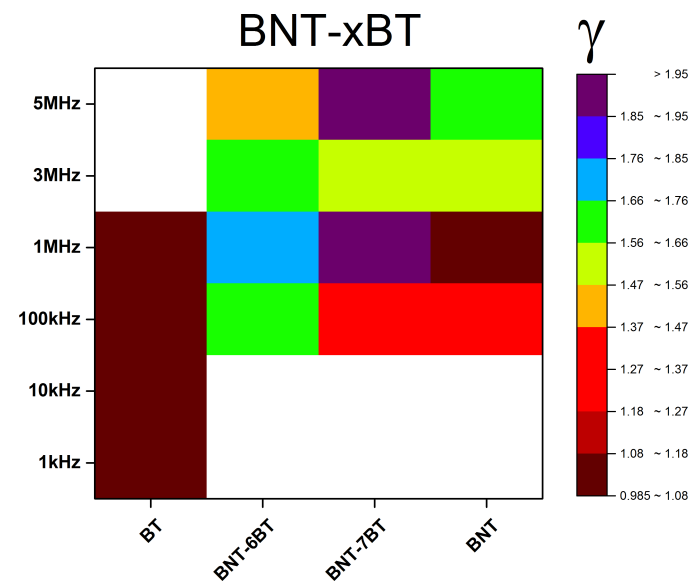

(a)

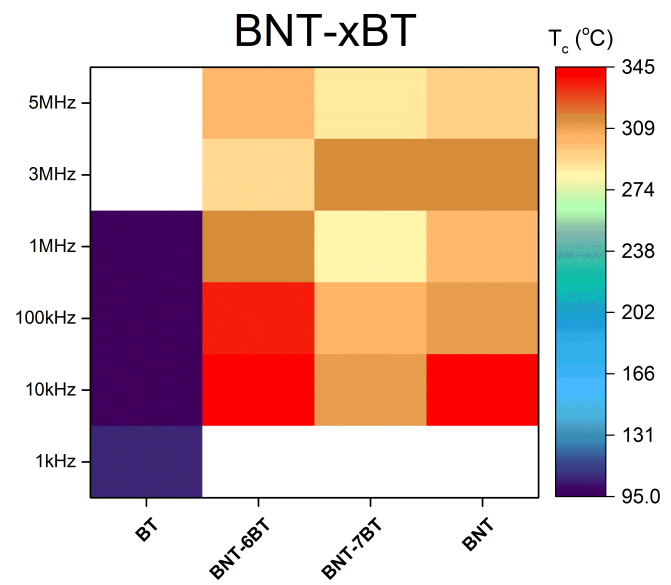

(b)

Fig. 7. Dielectric measurement results for BNT- $x$ BT system. 


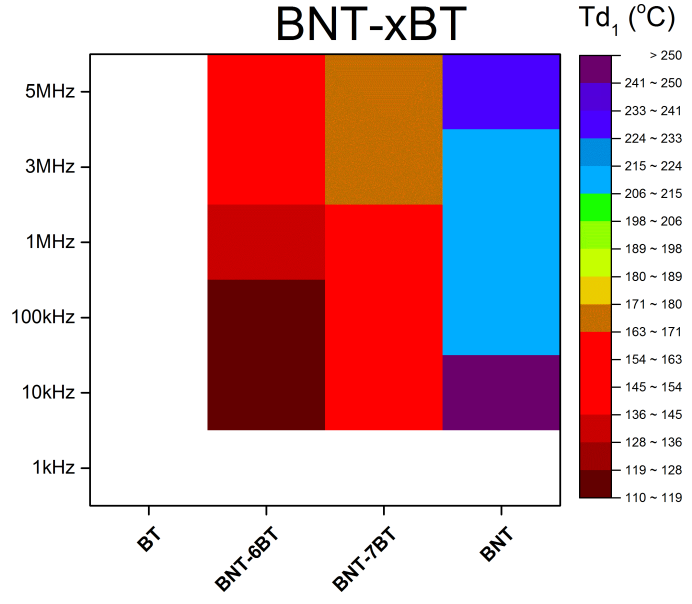

(c)

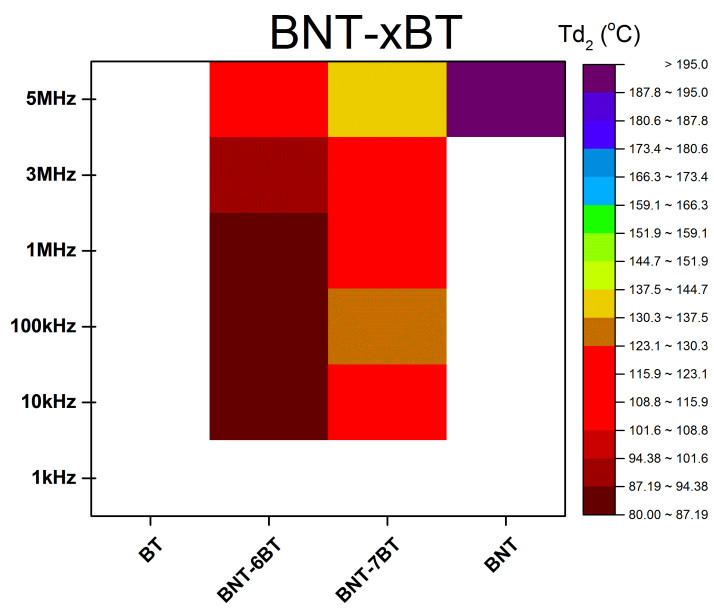

(d)

Fig. 7. (Continued)

increase, while the value of $T_{d 2}$ appeared at higher frequency only. Both the BNT-6BT and BNT-7BT samples showed depolarization values lower than BNT and decreased with frequency increase, as shown in Figs. 7(c) and 7(d).

\section{Conclusion}

The BNT- $x$ BT ceramic samples were prepared by hydrothermal processes with spherical particle shape in the range of $60-150 \mathrm{~nm}$, at $x=1,0.07,0.06$ and 0 . Both BNT-7BT and BNT-6BT samples showed MPB phase, so it had a high piezoelectric performance. The dielectric measurements showed that the BNT, BNT-7BT, BNT-6BT samples indicated as a relaxator behavior of ferroelectrics while the BT sample showed the normal ferroelectric behavior. The depolarization temperature in MPB region was decreased to about $80^{\circ} \mathrm{C}$ and became strongly dependent on frequency. The diffusion coefficient of transition at MPB region also strongly depended on frequency. When the frequency increased the diffusion coefficient also increased and the depolarization temperature decreased.

\section{References}

${ }^{1}$ S. Priya and S. Nahm, Lead-Free Piezoelectrics (Springer Science \& Business Media, 2011).

${ }^{2}$ G. O. Jones and P. A. Thomas, Investigation of the structure and phase transitions in the novel A-site substituted distorted perovskite compound $\mathrm{Na}_{0.5} \mathrm{Bi}_{0.5} \mathrm{TiO}_{3}$, Acta Crystallogr. B 58(2), 168 (2002).

${ }^{3}$ T. Oh and M.-H. Kim, Phase relation and dielectric properties in $\left(\mathrm{Bi}_{1 / 2} \mathrm{Na}_{1 / 2}\right)_{1-x} \mathrm{Ba}_{x} \mathrm{TiO}_{3} \mathrm{TiO}_{3}$ lead-free ceramics, Mater. Sci. Eng. B 132(3), 239 (2006).

${ }^{4} \mathrm{R}$. Machado et al., High stability of properties in morphotropic phase boundary $\mathrm{Bi}_{0.5} \mathrm{Na}_{0.5} \mathrm{TiO}_{3}-\mathrm{BaTiO}_{3}$ piezoceramics, Mater. Lett. 183, 73 (2016).
${ }^{5} \mathrm{~B}$. W. Lee et al., Phase transition behaviors of lead-free $\left(\mathrm{Na}_{1 / 2} \mathrm{Bi}_{1 / 2}\right) \mathrm{TiO}_{3}-\mathrm{BaTiO}_{3}$ single crystals studied by inelastic light scattering spectroscopy, Ferroelectrics 490(1), 43 (2016).

${ }^{6}$ K. Reichmann, A. Feteira and M. Li, Bismuth sodium titanate based materials for piezoelectric actuators, Materials 8(12), 8467 (2015).

${ }^{7}$ A. Chaouchi et al., Characterization of sol-gel synthesised leadfree $(1-\mathrm{x}) \mathrm{Na}_{0.5} \mathrm{Bi}_{0.5} \mathrm{TiO}_{3}-\mathrm{xBaTiO}_{3}$-based ceramics, J. Alloys Compd. 509(37), 9138 (2011).

${ }^{8}$ N. B. Mahmood and E. K. Al-Shakarchi, Three techniques used to produce $\mathrm{BaTiO}_{3}$ fine powder, J. Mod. Phys. 2(11), 1320 (2011).

${ }^{9} \mathrm{M}$. Cernea et al., Dielectric and piezoelectric behaviours of NBT$\mathrm{BT}_{0.05}$ processed by sol-gel method, J. Eur. Ceram. Soc. 32(1), 133 (2012).

${ }^{10} \mathrm{M}$. Cernea et al., Sol-gel synthesis and characterization of $\mathrm{BaTiO}_{3}$ -doped $\left(\mathrm{Bi}_{0.5} \mathrm{Na}_{0.5}\right) \mathrm{TiO}_{3}$ piezoelectric ceramics, J. Alloys Compd. 490(1-2), 690 (2010).

${ }^{11}$ G. Bergerhoff, M. Berndt and K. Brandenburg, Evaluation of crystallographic data with the program DIAMOND, J. Res. Natl. Inst. Stand. Technol. 101, 221 (1996).

${ }^{12}$ W. Pennington, DIAMOND - Visual Crystal Structure Information System, J. Appl. Crystallogr. 32(5), 1028 (1999).

${ }^{13}$ J. YI-Jian and L. J.-Z. Zeng Ling-Zhi, Neutron diffraction study of tetragonal barium titanate, Acta Phys. Sin. 37(4), 680 (1988).

${ }^{14}$ H. E. Swanson et al., Standard X-ray diffraction powder patterns. Vol. III, Data for 34 inorganic substances. National Bureau of Standards Circular 539, Volume 3. (National Bureau of Standards. II, Washington D. C., 1954) 73.

${ }^{15}$ PDF2, JCPDS-International Centre for Diffraction Data, Powder Diffraction File Newtown Square, Pennsylvania, (2003).

${ }^{16}$ R. H. Buttner and E. N. Maslen, Structural parameters and electron difference density in $\mathrm{BaTiO}_{3}$, Acta Crystallogr. B 48(6), 764 (1992).

${ }^{17} \mathrm{G}$. O. Jones and P. A. Thomas, The tetragonal phase of $\mathrm{Na}_{0.5} \mathrm{Bi}_{0.5} \mathrm{TiO}_{3}$ a new variant of the perovskite structure, Acta Crystallogr. B 56(3), 426 (2000).

${ }^{18}$ G. O. Jones, J. Kreisel and P. A. Thomas, A structural study of the $\left(\mathrm{Na}_{1-x} \mathrm{~K}_{x}\right)_{0.5} \mathrm{Bi}_{0.5} \mathrm{TiO}_{3}$ perovskite series as a function of substitution (x) and temperature, Powder Diffr. 17(4), 301 (2012). 
${ }^{19}$ ASTM, Test Methods for AC Loss Characteristics and Permittivity (Dielectric Constant) of Solid Electrical Insulation, ASTM International (2004).

${ }^{20}$ P. S. Silva, J. C. C. A. Diaz, O. Florêncio, M. Venet and J. C. M'Peko, Analysis of the phase transitions in BNT-BT lead-free ceramics around morphotropic phase boundary by mechanical and dielectric spectroscopies, Archives of Metallurgy and Materials 61(1), 17 (2016).

${ }^{21}$ J. Suchanicz, U. Lewczuk and K. Konieczny, Effect of Ba doping on the structural, dielectric and ferroelectric properties of $\mathrm{Na}_{0.5} \mathrm{Bi}_{0.5} \mathrm{TiO}_{3}$ ceramics, Ferroelectrics 497(1), 85 (2016).

${ }^{22} \mathrm{~J}$. Anthoniappen et al., Structural phase stability and electric field induced relaxer-ferroelectric phase transition in $(1-\mathrm{x})\left(\mathrm{Bi}_{0.5} \mathrm{Na}_{0.5}\right)$ $\mathrm{TiO}_{3}-\mathrm{xBaTiO}_{3}$ ceramics. J. Alloys Compd. 618, 120 (2015).
${ }^{23}$ R. Dittmer, Lead-Free Piezoceramics-Ergodic and Nonergodic Relaxor Ferroelectrics Based on Bismuth Sodium Titanate, in FB11 - Material and Geowissenschaften, Technische Universität, Darmstadt (2013).

${ }^{24}$ R. C. Smith and C. L. Hom, A temperature-dependent constitutive model for relaxor ferroelectrics. J. Intell. Mater. Syst. Struct. 16(5), 433 (2005).

${ }^{25}$ S.-T. Zhang, B. Yang and W. Cao, The temperature-dependent electrical properties of $\mathrm{Bi}_{0.5} \mathrm{Na}_{0.5} \mathrm{TiO}_{3}-\mathrm{BaTiO}_{3}-\mathrm{Bi}_{0.5} \mathrm{~K}_{0.5} \mathrm{TiO}_{3}$ near the morphotropic phase boundary. Acta Mater. 60(2), 469 (2012). 